\title{
O ACESSO À INTERNET COMO UM DIREITO FUNDAMENTAL
}

\author{
Rodrigo Mercedes do Espírito Santo ${ }^{1}$ \\ Andryelle Vanessa Camilo Pomin ${ }^{2}$
}

RESUMO: O Objetivo da presente pesquisa foi identificar a necessidade de elevar o acesso à internet a um direito fundamental. Para isso, foi escolhido o método bibliográfico, que permitiu demonstrar que, segundo a International Telecommunication Union (2019), agência da ONU, 49\% da população mundial ainda não tem acesso à internet, além dos riscos de violação de direitos como a privacidade para aqueles que possuem conexão. Sob o ponto de vista jurídico, foram apresentadas definições de direitos fundamentais e suas respectivas gerações e os dispositivos constitucionais sobre o assunto. Também foi feito um exercício para verificar se o acesso à internet constitui um direito fundamental. Além disso, a pesquisa mostrou que o acesso à internet pode ser visto como uma garantia fundamental, ou seja, como um meio de exercer outros direitos. Dessa maneira, concluiuse que o acesso à internet deve ser classificado como um direito fundamental, com o objetivo de gerar iniciativas do Estado que aumentem o acesso à rede e ao mesmo tempo protejam os direitos dos que a acessam.

Palavras-chave: Dignidade Humana; Internet; Novos Direitos.

ABSTRACT: The objective of this research was to identify the need to elevate internet access to a fundamental right. For this, the bibliographic method was chosen, which allowed us to demonstrate that, according to the International Telecommunication Union (2019), un agency, 49\% of the world's population does not yet have access to the Internet, in addition to the risk of violation of rights such as privacy for those who have a connection. From a legal point of view, definitions of fundamental rights and their respective generations and constitutional provisions on the subject were presented. An exercise has also been done to verify that internet access is a fundamental right. In addition, research has shown that internet access can be seen as a fundamental guarantee,

\footnotetext{
I Graduado em Gestão Pública pela UniCESUMAR - Centro de Ensino Superior de Maringá, Graduando em Ciência de Dados pela UNIVESP - Universidade Virtual do Estado de São Paulo. Servidor do Tribunal de Justiça do Estado de São Paulo.

${ }^{2}$ Mestre em Ciências Jurídicas. Professora do curso de graduação em Direito e de pós-graduação lato sensu da Unicesumar. Pesquisadora do CNPQ em Grupos vulneráveis e Novos Direitos. Advogada. Endereço eletrônico: <andryellecamilo@gmail.com.
} 
that is, as a means of exercising other rights. Thus, it was concluded that internet access should be classified as a fundamental right, with the aim of generating state initiatives that increase access to the network while protecting the rights of those who access it.

Keywords: Human Dignity; Internet; New Rights.

\section{INTRODUÇÃO}

O estudo busca entender se o acesso à internet é um direito fundamental, por meio de uma pesquisa bibliográfica que tem como objetivo vincular as bases jurídicas aos argumentos de fato. Nesse sentido, observou-se que a internet é uma estrutura complexa que vai além dos sites e aplicações visíveis para os usuários. As suas funções e a penetração ao redor do mundo dão ideia do quão importante ela se tornou nos dias atuais. Por outro lado, direitos fundamentais são direitos que pretendem proteger valores básicos de uma sociedade, com base na dignidade humana e nas demandas de seu respectivo tempo.

Desse modo, ao observar pesquisas e exemplos de fato ao redor do planeta, ficou claro que a internet é um direito fundamental e merece que o Estado a trate como protagonista para garantir um bom convívios social e as bases de um desenvolvimento individual.

\section{Aspectos gerais sobre a Internet}

\section{I O que é Internet?}

A Internet revolucionou definitivamente a sociedade moderna e a sua utilização está completamente inserida no cotidiano das pessoas: acessar uma conta bancária, cursar uma faculdade, controlar o aspirador de casa, pedir refeições, enfim, há um mundo novo assentado no acesso à rede mundial de computadores.

No entanto, o usuário final, ao interagir com as aplicações da rede (sites, aplicativos e outros serviços), não consegue decifrar o que é a Internet e entender como todas essas facilidades chegam até ele. Se por um lado isso não faz a menor diferença na hora de operar, por outro o impede de entender os riscos do mundo digital e todas as consequências de ter acesso a ele ou não.

A Internet é realmente uma rede de computadores, ou seja, é composta por máquinas capazes de processar dados e responder a comandos interligadas através de uma estrutura física (KUROSE, 2014, p. 3). Nessa estrutura, em suma, os sistemas finais (computadores, TVs, smartphones e outros) se conectam à rede por meio de Provedores de Serviços Locais (conhecidos como Provedores de Internet), que por sua vez se conectam à rede global. Dessa maneira, as informações podem circular de ponta a ponta e quaisquer dispositivos podem trocar informações entre si, desde que estejam conectados à rede.

Esse modelo é comparável ao mundo real, em que os imóveis seriam os sistemas finais, os provedores de serviços e a estrutura física seriam o sistema rodoviário, e os automóveis, os portadores da informação a ser transportada. 
Para Ronaldo Lemos, "é equivocado supor que esse formato em rede vai resolver questões que herdamos de outros tempos. A tecnologia e a configuração em rede conseguem lidar com algumas questões, mas acarretam outras que são igualmente importantes e desafiadoras, como a questão da privacidade” (LEMOS, 2015, p. II). Essa configuração é, portanto, o grande trunfo da internet e, ao mesmo tempo, uma fonte de novos problemas.

\subsection{Origem e evolução histórica}

A Internet, como se conhece hoje, não possui uma data específica de criação, tampouco tem origem em um fenômeno específico. Ela é fruto de diversos experimentos e conhecimentos acumulados ao longo do tempo, em diversos lugares do planeta. É, portanto, uma construção coletiva em que empresas, governos, universidades e cidadãos colaboraram.

No entanto, alguns fatos e algumas pessoas foram mais marcantes ou tiveram um impacto maior no desenvolvimento da rede mundial de computadores. Nesse sentido, a ARPANET, um projeto do Departamento de Defesa Americano iniciado nos anos sessenta, ficou conhecida como a precursora da Internet, pois criou a base lógica da comunicação em rede que se utiliza hoje. Esse projeto tinha como objetivo imediato economizar dinheiro, fazendo com que uma máquina pudesse compartilhar seus recursos com outras máquinas interligadas entre si (ROSA, 2012, p. 95-123). Contudo, o trabalho de um pesquisador chamado Paul Baran teve grande influência sobre a ARPANET, fazendo com que os objetivos de seus estudos se confundissem aos do projeto. Para Baran o foco era criar uma rede de comunicação que resistisse a ataques soviéticos. Ele entendia que, sem um ponto central, o sistema poderia sobreviver caso algumas de suas partes fossem destruídas?3.

Nos anos 80 a Internet começou a se popularizar no meio acadêmico e começaram a surgir as primeiras empresas fornecendo acesso, conhecidas como Provedores (INTERNET SOCIETY, 2019). Desde então o crescimento foi exponencial e naturalmente chamou atenção do setor econômico, sempre em busca de eficiência. Dessa maneira, a internet, aliada aos equipamentos tecnológicos, tem impactado os meios de produção, de comércio e consumo e ajudado a construir uma sociedade completamente nova.

\subsection{Utilização no Brasil e no mundo}

A rede mundial de computadores é uma tecnologia que está sempre vinculada aos dispositivos físicos, como smartphones, máquinas de diversos usos, TVs, entre outros. Por isso, a popularização da Internet acompanhou a desenvolvimento tecnológico desses aparelhos, conforme eles iam ganhando mercado, a Internet ia crescendo. Um exemplo disso é o crescimento do mercado de smartphones, que hoje já atinge mais de 5 bilhões de usuários únicos, segundo a GSMA, associação das indústrias do setor, sendo que 3,3 bilhões o utilizam para acessar a Internet (GSMA, 2019).

É natural, portanto, que a rede continue crescendo e venha alcançando cada vez mais pessoas. Pela primeira vez na história mais da metade da população mundial (51\%) já tem acesso à internet, ou seja, 3,9 bilhões de pessoas (INTERNET TELECOMMUNICATION UNION, 2019). No entanto, ainda há lugares no mundo em 
que a internet não chega, principalmente por questões políticas e a relação de governos com elas.

Para demonstrar isso, a presente pesquisa cruzou informações de dois estudos: o ranking de penetração da internet ${ }^{3}$, feito pela We Are Social, agência global especializada em mídias sociais; e a classificação de países conforme sua liberdade ${ }^{4}$, elaborada pela ONG mericana Freedom House. Conforme demonstra quadro abaixo:

\begin{tabular}{|c|c|c|c|c|c|c|}
\hline Maiores Penetrações & $\%$ & Usuários & $\mathbf{L}$ & Menores Penetrações & $\%$ & Usuários \\
\hline Andorra & $99 \%$ & 76.242 & & Coréia do Norte & $0,08 \%$ & 20.000 \\
\hline Aruba & $99 \%$ & 104.803 & & Eritrea & $1,40 \%$ & 71.000 \\
\hline Bermuda & $99 \%$ & 60.342 & & Chad & $5,00 \%$ & 779.188 \\
\hline Islândia & $99 \%$ & 335.781 & & República Centro-Africana & $5,40 \%$ & 256.432 \\
\hline Qatar & $99 \%$ & 2.692 .181 & & Burundi & $5,40 \%$ & 617.116 \\
\hline Emirados Árabes Unidos & $99 \%$ & 9.515 .733 & & Rep. Democrática do Congo & $6,20 \%$ & 5.301 .224 \\
\hline Noruega & $99 \%$ & 5.311 .892 & & Guiné-Bissau & $7,80 \%$ & 150.000 \\
\hline Dinamarca & $98 \%$ & 5.649 .494 & & Somália & $9,70 \%$ & 1.500 .000 \\
\hline Kuwait & $98 \%$ & 4.138 .590 & & Madagascar & $9,80 \%$ & 2.608 .390 \\
\hline Luxemburgo & $98 \%$ & 580.760 & & Nigéria & $10,00 \%$ & 2.325 .421 \\
\hline
\end{tabular}

I - Ranking de penetração da Internet por país - Fonte: o Autor

Dessa maneira, observa-se, para além do ranking de nações, que o nível de penetração da internet em um país tem relação direta com sua liberdade, apesar de não ser possível observar se esta afeta aquela ou vice-versa. Porém, ao analisar casos como o da Coréia do Norte, do Qatar e do Emirados Árabes é possível entende melhor essa relação.

A Coréia do Norte ganha destaque por ser o país com menor penetração da rede no mundo. Isso acontece porque bloquear o acesso da população à internet é uma política de Estado naquele país (THE SUN, 2019). Já Qatar e Emirados Árabes possuem populações extremamente conectadas, no entanto, têm um sistema de censura e filtragem muito bem estabelecidos (OPEN NET INITIATIVE, 2019). Esses países demonstram que governos podem violar direitos de acesso à internet dos cidadãos de maneiras diferentes e sugerem que a rede é um agente de transformação poderoso e um meio de controle social.

O Brasil, por sua vez, segue a tendência global e cerca de $70 \%$ das pessoas já tem acesso à rede (IBGE, 2017). No entanto, a classe social ainda impacta a possibilidade de acesso à internet. Segundo a pesquisa TIC Domicílios 2017, 47\% dos indivíduos das classes $\mathrm{D} / \mathrm{E}$ e $21 \%$ classe $\mathrm{C}$ declararam nunca ter acessado a rede mundial de computadores (IBGE - TIC, 2017). A Tabela abaixo apresenta mais detalhes:

\footnotetext{
${ }^{3}$ WE ARE SOCIAL. Digital in 2019. Disponível em: https://wearesocial.com/global-digital-report-2019. Acesso em: 23 jun. 2019.

4 FREEDOM HOUSE. Democracy in Retreat: Freedom In The World 2019. Disponível em: https://freedomhouse.org/report/freedom-world/freedom-world-2019/map. Acesso em: 23 jun. 2019.

Revista Ibero-Americana de Humanidades, Ciências e Educação. São Paulo, v.7.n.4.abr. 2021.
} 


\section{Pessoas que já acessarama internet}

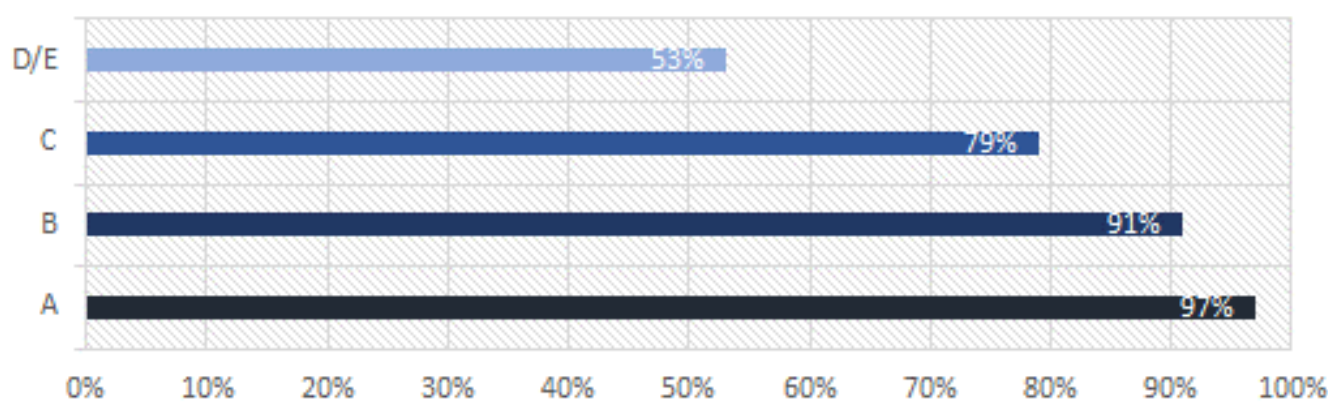

2- Indivíduos que já acessaram a internet por classe social - Fonte: o autor

Assim, observa-se que, apesar da tendência global de popularização da internet, há desafios regionais heterogêneos a serem superados, que demandam soluções específicas e adaptadas a realidade de cada país.

\subsection{Funções da Internet}

$\mathrm{O}$ acesso à rede mundial de computadores tem se transformado em um poderoso agente de transformação social e individual, isso porque executa funções das mais variadas, que afetam tanto a estrutura de uma sociedade quanto aspectos particulares de um ser.

O impacto na sociedade atual pode ser visto principalmente na revolução dos meios de produção. Para o economista americano Jeremy Rifkin, autor do livro "The Third Industrial Revolution", a Internet e a produção de energia descentralizada serão capazes de criar um modelo produtivo completamente novo (INSTITUTO HUMANITAS UNISINOS, 2019). Já para Erik Brynjolfsson e Andrew McAfee, professores do Instituto de Tecnologia de Massachusetts (MIT), as fábricas inteligentes, fundadas em digitalização e automação, são a grande transformação do setor industrial (EXAME, 2019).

Além disso, outros tipos de serviços estão reprogramando a vida em sociedade. Em Barcelona, por exemplo, devido a tecnologia de Internet das Coisas, foi possível fornecer iluminação pública automatizada, irrigação controlada remotamente para parques e fontes, coleta de lixo sob demanda, rotas de ônibus digitais e parquímetros inteligentes, segundo o Fórum Econômico Mundial (WORLD ECONOMIC FORUM, 2019). Na Europa, já se planeja um sistema de trânsito com carros conectados uns aos outros, que, por exemplo, freariam em sincronia, eliminando semáforos (FOLHA DE SÃO PAULO, 2019).

Já como agente de transformação individual, deve se observar as diversas funções assumidas pela internet: pedir comida, comunicar-se, trabalhar, entre outras. Para que se possa ter um parâmetro mais tangível em relação ao seu impacto sobre um indivíduo, é importante entender a Hierarquia das Necessidades Humanas, teoria da psicologia muito utilizada no ramo da administração e desenvolvida por Maslow. Segundo essa teoria, também conhecida como pirâmide de Maslow, as necessidades do ser humano podem ser organizadas em níveis hierárquicos, assim cada indivíduo busca satisfazê-las começando pelos níveis mais baixos até alcançar os mais altos (MASLOW, 1948, p 370-396). 
Segundo Maslow, o primeiro nível é o fisiológico, que representa necessidades básicas, como comer, beber, dormir, respirar, etc.; já o segundo se relaciona com as necessidades de segurança, como ter uma casa, um emprego, acesso a médicos, entre outros; as necessidades sociais estão no terceiro nível e englobam as relações humanas, como ter amigos, ter uma família, receber e dar afeto, e outros; o quarto se refere as necessidades de estima, que incluem o reconhecimento dos outros sobre as capacidades do indivíduo, ter prestígio, orgulho, poder; já o quinto e último nível se refere à auto realização, ou seja, o desejo de aproveitar todo o próprio potencial, de obter autonomia e independência (MASLOW, 1948, p 370-396).

Nesse sentido, a presente pesquisa classificou alguns serviços e aplicativos de internet dentro das categorias definidas por Maslow de acordo com suas funções principais, conforme quadros abaixo:

\begin{tabular}{|c|c|c|}
\hline & Aplicativo & Função \\
\hline $\mathbf{M}$ & Medium & Divulgar trabalhos intelectuais e artísticos \\
\hline & You Tube & Produzir e divulgar vídeos \\
\hline & Instagram & Divulgar fotos pessoais \\
\hline & WhatsApp & Comunicar-se \\
\hline & Tinder & Encontrar relações amorosas \\
\hline
\end{tabular}

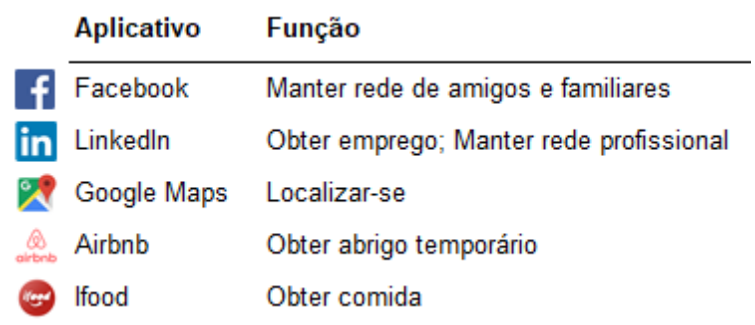

3 - Aplicativos e suas funções. Fonte: o autor

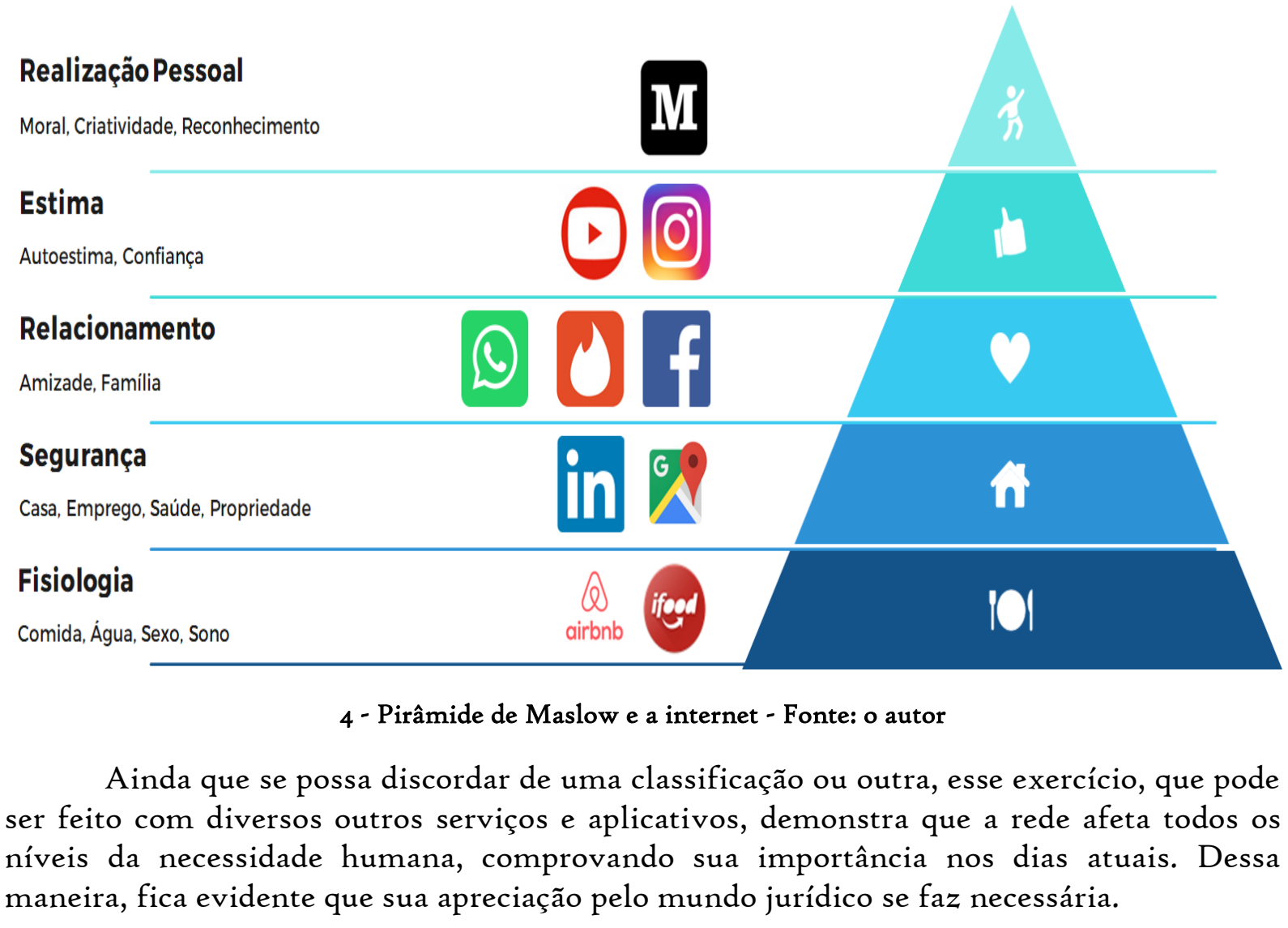




\section{Direitos Fundamentais}

\section{I Aspectos Gerais sobre Direitos Fundamentais}

Os direitos fundamentais são frutos de lutas e conquistas progressivas de uma sociedade. Para Alexandre de Moraes,

são o conjunto institucionalizado de direitos e garantias do ser humano que tem por finalidade básica o respeito a sua dignidade, por meio de sua proteção contra o arbítrio do poder estatal e o estabelecimento de condições mínimas de vida e desenvolvimento da personalidade humana (MORAES, I997, p. 39).

Já para Perez Luño,

são um conjunto de faculdades e instituições que, em cada momento histórico, concretizam as exigências da dignidade, da liberdade e da igualdade humanas, as quais devem ser reconhecidas positivamente pelos ordenamentos jurídicos em nível nacional ou internacional (CASTRO, LUÑO, CID, TORRES, 1979, p. 43).

Há outras tantas definições, no entanto, percebe-se a dignidade humana como valor base para os direitos fundamentais em todas elas.

Para o Supremo tribunal Federal (STF),

a dignidade da pessoa humana é "significativo vetor interpretativo, verdadeiro valor-fonte que conforma e inspira todo o ordenamento constitucional vigente em nosso País e que traduz, de modo expressivo, um dos fundamentos em que se assenta, entre nós, a ordem republicana e democrática consagrada pelo sistema de direito constitucional positivo. ${ }^{5}$

Vale lembrar que as ideias que hoje estão consagradas como direitos fundamentais nas constituições ao redor do mundo eram, na verdade, conhecidas como direitos do homem, muito antes de haver um ordenamento jurídico escrito, e representavam valores ligados à liberdade, dignidade, igualdade e solidariedade. Esses valores também eram, e ainda são, encontrados nos códigos morais da humanidade, como as religiões, e são pilares de um convício social pacífico e um pleno desenvolvimento individual (MARMELSTEIN, 2018, p. 20).

\subsection{Gerações de Direitos Fundamentais}

Os direitos fundamentais podem ser divididos em três gerações, cada uma delas representando um grupo de direitos conquistados em determinado momento.

Os primeiros direitos fundamentais surgiram com o objetivo de sanar um problema: a ingerência do Estado na vida dos cidadãos, ou seja, visavam proteger as

${ }^{5}$ STF - HC: 97476 RJ, Relator: Min. CELSO DE MELLO, Segunda Turma, Data de Publicação: DJe-223 DIVULG 26-11-2009 PUBLIC 27-11-2009 EMENT VOL-02384-03 PP-00492

Revista Ibero-Americana de Humanidades, Ciências e Educação. São Paulo, v.7.n.4.abr. 2021. 
liberdades do indivíduo, estabelecendo um dever de 'não fazer' do Estado, um comportamento omissivo (PAULO, ALEXANDRINO, 20I6, p. 453). São os direitos civis e políticos: à vida, à propriedade, à liberdade de expressão, à participação política, etc. Surgiram no Século XVIII e são o marco da mudança do Estado absoluto para o Estado liberal.

Os direitos de segunda geração fortalecem o princípio da igualdade. São, em linhas gerais, os direitos econômicos, sociais e culturais. $\mathrm{Na}$ prática, representam um dever de agir do Estado, pois só podem ser efetivados por meio da implantação de políticas e serviços públicos, como saúde, educação e trabalho. Marcam também a passagem do Estado liberal para o Estado social, mais focado em garantir o bem-estar comum.

Já os direitos fundamentais de terceira geração visam proteger todo o gênero humano, não pertencem a um Estado ou a um indivíduo, são direitos de titularidade difusa. Os principais exemplos são os direitos à paz, ao meio ambiente ecologicamente equilibrado, ao patrimônio da humanidade, entre outros. Consolidam os princípios da solidariedade e da fraternidade.

Há atualmente alguns autores, como José Alcebíades de Oliveira Júnior ${ }^{6}$ e Cesar Luiz Pasold 7 , que enxergam ainda outras duas gerações de direitos fundamentais: a quarta geração, que abrange os direitos à democracia, à informação e ao pluralismo; e a quinta geração, que engloba os direitos tecnológicos.

\subsection{Os direitos fundamentais e a Constituição Brasileira}

Identificar um direito fundamental não é uma tarefa fácil. Há teorias que propõem caminhos para essa missão, mas em todas há um grau de abstração elevado. Um caminho possível é vincular valores ou princípios de justiça ao "fundamento de direitos fundamentais", conforme propõe Luigi Ferrajoli em uma de suas abordagens para o tema. Para o autor deve-se tentar responder a seguinte pergunta: "Quais direitos devem ser garantidos como fundamentais?" Para isso, em suma, ele estabelece quatro valores como critérios: a dignidade da pessoa, a igualdade, a tutela dos mais fracos e a paz (FERRAJOLI, 2011, pos. 2394-2399) .

Nesse sentido, percebe-se que Supremo tribunal Federal segue caminho parecido, contudo, busca esses valores na carta magna. Segundo Mendes e Branco, o "STF é sensível à identificação de normas de direito fundamental fora do catálogo específico, a partir do exame da existência de um especial vínculo do bem jurídico protegido com alguns dos valores essenciais ao resguardo da dignidade humana enumerados no caput do art. $5^{\circ}$ da Carta." (MENDES, BRANCO, 2012, p. 211-212)

\footnotetext{
${ }^{6}$ OLIVEIRA JÚNIOR, José Alcebíades de. Teoria Jurídica e Novos Direitos. Rio de Janeiro: Lumen Juris, 2000 , p. 86.

${ }^{7}$ PASOLD, Cesar Luiz. Novos Direitos: conceitos operacionais de cinco categorias que lhes são conexas. Revista Sequência, n. 50, jul. De 2005, p. 224. 
Desse modo, a Constituição federal estabelece em seu art. $5^{\circ}$ que "todos são iguais perante a lei, sem distinção de qualquer natureza, garantindo-se aos brasileiros e aos estrangeiros residentes no País a inviolabilidade do direito à vida, à liberdade, à igualdade, à segurança e à propriedade...”

Vale lembrar ainda dois fatores importantes sobre o tema inseridos na carta magna: o princípio da não tipicidade dos direitos fundamentais e a proteção jurídica especial atribuída a eles. O primeiro permite a introdução de novos direitos como fundamentais. Isso está previsto no art. $5^{\circ}$, $\S^{2}$ - : "os direitos e garantias expressos nesta Constituição não excluem outros decorrentes do regime e dos princípios por ela adotados, ou dos tratados internacionais em que a República Federativa do Brasil seja parte" (CONSTITUIÇÃO DA REPÚBLICA FEDERATIVA DO BRASIL, 1988). Já a proteção jurídica deriva do fato de que, no Brasil, os direitos fundamentais estão inseridos no texto constitucional e só poderão ser alvo de mudança através de um Projeto de Emenda Constitucional que obtenha a aprovação, em dois turnos, de $3 / 5$ dos membros de cada casa legislativa. Alguns autores inclusive defendem que os direitos fundamentais são cláusulas pétreas e, portanto, não estão sujeitos à exclusão ou modificação.

Percebe-se, portanto, que a Constituição brasileira além de elencar direitos fundamentais, busca protegê-los, é receptiva a novos e ainda sugere um caminho para identificar bens jurídicos merecedores do título de direito fundamental.

\subsection{O Acesso à Internet como Direito Fundamental}

A internet vem crescendo de maneira exponencial, a cada ano ela está mais popularizada e mais enraizada na vida do ser humano. Nesse sentido, Bobbio afirmou:

\footnotetext{
Não é preciso muita imaginação para prever que o desenvolvimento da técnica, a transformação das condições econômicas e sociais, a ampliação dos conhecimentos e a intensificação dos meios de comunicação poderão produzir tais mudanças na organização da vida humana e das relações sociais que se criem ocasiões favoráveis para o nascimento de novos carecimentos e, portanto, para novas demandas de liberdade e de poderes (BOBBIO, 2004, p. 21).
}

Luigi Ferrajoli também destacou, ao falar da importância dos direitos sociais, que sobreviver no mundo atual é cada vez menos um fato natural e mais um fato artificial dependente da integração social (FERRAJOLI, 20II, pos. 247I).

Nesse sentido e diante da notória velocidade de expansão da rede e das necessidades que ela tem criado, a sociedade carecia de tratamento jurídico sobre tema. No Brasil, o Marco Civil da Internet desempenhou esse papel. A lei ${ }^{\circ}{ }^{\circ} 2.965 / 2014$ foi discutida, em grande parte na própria rede, durante 7 anos e ganhou notoriedade por ser a primeira grande experiência de uma construção legislativa coletiva fora dos tradicionais espaços institucionais (SOUZA, LEMOS, 2016).

Essa lei reconheceu, em seu art. $7^{\circ}$, que "o acesso à internet é essencial ao exercício da cidadania..." (MARCO CIVIL DA INTERNET, 2014). Além disso, trouxe outras importantes contribuições, com destaque para a neutralidade da rede e a privacidade. 
Em relação à neutralidade da rede, o texto da lei garante que "o responsável pela transmissão, comutação ou roteamento tem o dever de tratar de forma isonômica quaisquer pacotes de dados, sem distinção por conteúdo, origem e destino, serviço, terminal ou aplicação" (MARCO CIVIL DA INTERNET, 20I4). Ou seja, os usuários são tratados de maneira igual independente de qual conteúdo ou de qual plataforma acessem a internet. Esse é um ponto importante porque não permite, entre outras coisas, que os provedores cobrem mais para quem acessa determinados sites ou serviços.

Já no que diz respeito à privacidade, o Marco Civil da Internet reforça "a preservação da intimidade, da vida privada, da honra e da imagem das partes direta ou indiretamente envolvidas" (MARCO CIVIL DA INTERNET, 2014). Esse é um instituto extremamente relevante, visto que ao se conectar à internet o usuário está vulnerável a uma invasão, que pode controlar dispositivos físicos, como a webcam, ou sequestrar arquivos importantes de seu terminal. Além disso, ao navegar pela rede, dados são coletados a todo o momento, gerando uma fonte rica de informações para empresas, governos e políticos e um ponto de fragilidade para os cidadãos.

Um caso extremamente grave, ocorrido nos últimos anos, deixou clara a importância do tema privacidade. Em 2013, os jornais "The Guardian" e "The Washington Post” revelaram um sistema de vigilância global da Agência Nacional de Segurança dos Estados Unidos. Por meio de documentos obtidos por Edward Snowden, ex-agente da instituição, o mundo descobriu que o governo dos EUA monitorava as atividades de diversos cidadãos no mundo todo, seja coletando seus dados na internet, seja interceptando conteúdos gerados por dispositivos físicos como microfone e webcam (EL PAÍS, 2019).

Vale ressaltar que em 2018 foi aprovada a Lei Geral de Proteção dos Dados, que definiu fundamentos, princípios e normas para o tratamento de dados pessoais no território nacional.

Diante desse cenário fica claro que o acesso à internet vem tendo sua relevância reconhecida também no mundo jurídico, e parece inevitável que o próximo passo seja reconhecê-lo como um direito fundamental, devido ao seu impacto no mundo atual. Nesse sentido, elaborou-se uma comparação de fatos e pesquisas recentes e relevantes com alguns dos valores básicos elencados no art. $5^{\circ}$ da Carta Magna brasileira, com o objetivo de simular, de forma simplificada, o que faz o STF para identificar normas de direitos fundamentais fora do catálogo específico.

O primeiro direito elencado é o direito à vida. Esse valor básico tradicionalmente corresponde ao direito de estar vivo e de manter a própria vida, mas também "aparece vinculado aos direitos a integridade física, a alimentação adequada, a se vestir com dignidade, a moradia, a serviços médicos, ao descanso e aos serviços sociais indispensáveis" (MENDES, BRANCO, 2012, p. 380).

Quanto ao direito de manter a própria vida, o acesso à rede tem ajudado na denúncia de crimes em geral, mas especialmente daqueles que acontecem em zonas remotas e de constantes conflitos. No interior do Maranhão, por exemplo, a internet comunitária permite que quilombolas denunciem pistoleiros sem que tenham que se dirigir fisicamente às autoridades, o que frequentemente causava riscos à vida dos denunciantes, 
segundo a presidente da Associação das Comunidades Quilombolas de Penalva (UOL, 2019).

Além disso, em um mundo capitalista como o atual, é impossível dissociar a capacidade de viver com dignidade do dinheiro. Nesse sentido, segundo estimativa da consultoria Deloitte (2014), uma significativa expansão no acesso à Internet pode gerar um aumento médio nos rendimentos per capita de cerca de $15 \%$ nos países em desenvolvimento. Na África e na Índia, onde os níveis de renda são os mais baixos e o aumento na penetração (expansão) têm o potencial de ser mais alto, o acesso à Internet pode aumentar a renda "per capita" em 21\% e 29\% respectivamente (DELOITTE, 2019).

Já sob o ponto de vista da liberdade, outro valor básico previsto no art. $5^{\circ}$, a internet exerce hoje papel de absoluta importância. Ficou demonstrado pela presente pesquisa, ao cruzar os dados de penetração da rede e a classificação de liberdade dos países, que a internet se relaciona diretamente com esse valor.

No entanto, para ir adiante é preciso observar o impacto da internet em algumas das liberdades. A liberdade de expressão, por exemplo, que consiste basicamente no direito de comunicar-se e receber informações, é exercida precipuamente na internet nos dias de hoje, afinal, 3,5 bilhões de pessoas em todo mundo possuem contas em redes sociais (WE ARE SOCIAL, 2019), principal ferramenta de comunicação da rede. No Brasil, por exemplo, $95 \%$ das pessoas usam a internet para trocar mensagens em aplicativos, é o que demonstra pesquisa do IBGE.

Isso revela dois pontos importantes: as pessoas que estão impedidas de acessar à rede estão também sem poder se comunicar instantaneamente e em larga escala; por outro lado aqueles que podem acessar à internet devem usufruir de alguns direitos que garantam a não interferência estatal e de empresas nas suas escolhas online.

A liberdade profissional também é afetada pela internet. Segundo pesquisa da agência de empregos Catho, divulgada pela revista EXAME, procurar emprego em sites online é uma das opções para $65 \%$ dos candidatos, ocupando a primeira posição. Isso demonstra a importância do acesso à rede na escolha da atividade profissional e no seu respectivo sucesso.

O terceiro direito elencado no art. $5^{\mathrm{O}}$ é o da igualdade, que se divide em igualdade formal e material. Esta se refere à igualde real, ou seja, a busca por reduzir as desigualdades entre os cidadãos, já aquela se refere à igualdade jurídica, ou seja, o dever do Estado e das leis de tratar as pessoas de maneira isonômica. Esse valor básico também é bastante influenciado pela rede mundial de computadores. Uma das oportunidades geradas recentemente e que mais tem causado impacto positivo é a possibilidade de estudar nas melhores faculdades do mundo completamente a distância, a limitação física das salas de aula tradicionais está sendo superada pela internet. Instituições como Harvard e MIT (Massachusetts Institute of Technology), que sempre estiveram no topo do ensino mundial estão sendo democratizadas a partir de internet. Ações como essa colocam pessoas em condições de igualdade para competir pelas oportunidades geradas diariamente e para cooperar com uma sociedade mais desenvolvida. 
Os valores da vida, liberdade e igualdade estão vinculados diretamente à dignidade humana, que, como demonstrado, é o centro dos direitos fundamentais, no entanto, a internet permeia outros tantos direitos e setores da vida em sociedade, o que demonstra sua importância e desenha as bases para considera-la um direito em si mesma.

Foi nesse sentido que, em 2010, na Finlândia, o acesso à Internet foi reconhecido por lei como um direito básico e garantido a todo cidadão um acesso com velocidade de, no mínimo, I megabit por segundo (BBC, 2019). Já a ONU, um ano depois, concluiu que o acesso à Internet é um direito humano quando declarou que "desconectar pessoas da internet é uma violação dos direitos humanos” (GLOBO.COM, 2019).

Ao juntar todas essas peças, percebe-se que a Internet é hoje um alicerce para um novo mundo que vem sendo criado. Os que ficam sem acesso à rede mundial de computadores ficam também restritos a viver em mundo ultrapassado, com oportunidades limitadas e sem chances de definir seus futuros. Já os que podem acessá-la estão sujeitos a diversos tipos de violação de direitos, que ferem principalmente sua autonomia enquanto cidadão. E por esses motivos o amparo jurídico tem se revelado cada vez mais importante.

\subsection{O Acesso à Internet como Garantia Fundamental}

Há que se ressaltar que o acesso à internet, além de um direito em si mesmo, pode ser visto também como uma garantia fundamental, ou seja, um instrumento por meio do qual se assegura o exercício de outros direitos.

Alexandre de Moraes revela:

A distinção entre direitos e garantias fundamentais, no Direito brasileiro, remonta a Rui Barbosa, ao separar as disposições meramente declaratórias, que são as que imprimem existência legal aos direitos reconhecidos, e as disposições assecuratórias, que são as que, em defesa dos direitos, limitam o poder. Aquelas instituem os direitos; estas, as garantias; ocorrendo não raro juntar-se, na mesma disposição constitucional, ou legal, a fixação da garantia, com a declaração do direito. (MORAES, 1997, p. 8I)

Bem, ao longo deste estudo diversas pesquisas e dados foram apresentados e naturalmente vinculavam a internet ao exercício de outros direitos, entre outras coisas. Isso se deve ao perfil multifacetado da rede e também ao fato de ser uma espécie de direito base, em que ao exercer outros direitos, exerce-se também o direito de acesso à internet. Isso pode ser visto mais claramente com o direito à vida, por exemplo. Ao exercer o direito à liberdade, uma pessoa está necessariamente usufruindo do seu direito à vida.

Desse modo, a internet pode ser garantia para o usufruto de inúmeros direitos, no entanto, para restringir o objeto do estudo, a presente pesquisa elegeu os direitos políticos como exemplo, devido à sua importância para o Estado Democrático de Direito e para a construção de uma sociedade livre, justa e solidária. 


\section{O Acesso à Internet e a reafirmação de outros Direitos}

\section{I Direitos Políticos e Teledemocracia}

Os Direitos Políticos são a pedra angular de uma democracia. Por intermédio deles que o povo pode exercer sua soberania. Por isso, é preciso que o ordenamento jurídico acompanhe a evolução social para que esses direitos possam ser gozados em sua mais absoluta plenitude.

O exercício desses direitos pela internet é conhecido como Teledemocracia e Cibercidadania e já possuem exemplos relevantes em curso no mundo inteiro. $\mathrm{O}$ de mais fácil visualização são os grandes protestos convocados e organizados por meio das redes sociais. A primavera Árabe, por exemplo, não aconteceria se não fosse essa ferramenta, é o que diz um estudo da "Dubai School of Government". De acordo com esse relatório, nove em cada dez egípcios e tunisianos afirmaram ter usado o Facebook para organizar ou participar dos protestos. Na Tunisia, o resultado disso foi a queda de Zine El Abidine Ben Ali, que estava no poder há 23 anos (DUBAI SCHOOL OF GOVERNMENT, 2019).

Não é à toa que regimes com tendências autoritárias tentam controlar a internet $e$ até mesmo desenvolver sua própria rede. $\mathrm{Na}$ China, por exemplo, um robusto modelo de censura digital tenta barrar conteúdos de diversos tipos (SUPER INTERESSANTE, 2019). Já na Rússia tramita um projeto de lei com o objetivo de criar uma rede Russa, ou seja, uma internet própria completamente desconectada da rede global. (ÉPOCA NEGÓCIOS, 2019)

Outro exemplo importante foi a influência dos dados pessoais na Eleição americana de 2016. O jornal britânico "The Guardian", em 2018, revelou que a empresa "Cambrige Analytica" usou dados de mais de 50 milhões de usuários do Facebook, sem seus consentimentos, para propaganda política. O objetivo dessa prática era mandar mensagens personalizadas, nem sempre verdadeiras, pró-Trump, ou contra seus adversários, de maneira que aumentasse a probabilidade de convencer seus respectivos destinatários (BBC, 2019). Fatos como esses reforçam a necessidade de um instrumento jurídico que regule e garanta direitos no ciberespaço.

Além disso, quando o tema é teledemocracia e cibercidadania, outros pontos ganham destaque. A participação popular na subscrição de projetos de lei tem se tornado cada vez mais adotada, não são raras as vezes em que circulam nas redes iniciativas de lei que ganham apoio massivo da população. Do mesmo modo, os congressistas têm usado a internet para definir seus votos. Recentemente o senador Jorge Kajuru usou sua página no Facebook para consultar os eleitores sobre o voto que deveria dar na eleição para a presidência do Senado (CONGRESSO EM FOCO, 2019).

Essa participação cada vez mais forte da população e as novas formas de organizações dos movimentos sociais podem formar, em um futuro próximo, uma democracia muito mais robusta e substituir o modelo indireto, que existe atualmente. É justamente esse um dos principais pontos que defende Perez Luño:

La teledemocracia, en su versión "fuerte", representa un instrumento para hacer viables determinadas experiencias políticas de democracia directa que, 
anteriormente, resultaban muy problemáticas. Los defensores de esta aplicación tecnológica entienden, asimismo, que esta nueva versión de la participación democrática no constituye una mera ampliación de los medios políticos, sino que entraña un auténtico salto cualitativo hacia una nueva forma de sociedad. (LUÑO, 2014, p. 8-46)

Desse modo, percebe-se que a internet está mudando completamente o exercício dos direitos políticos e está criando as bases para uma democracia ainda mais profunda, que poderá transformar a vida em sociedade.4.2 Como o Estado pode promover a garantir o acesso à Internet

Diante de direito tão importante como o acesso à internet, o Estado deve atuar em duas frentes: de um lado manter um comportamento omissivo, com o intuito de preservar as liberdades dos usuários. De outro, uma atitude comissiva que busque prover o acesso ao maior número possível de cidadãos e garanta que esse acesso atenda a princípios básicos, como a privacidade, a liberdade, a neutralidade da rede, entre outros.

Nesse sentido, em 2015, o Tribunal de contas da União elaborou um estudo sobre os programas de inclusão digital realizados no Brasil até então (TCU, 2019). O principal problema detectado pelo órgão é a falta de integração e articulação das diversas ações. Apesar disso, as iniciativas existem em bom número e podem ser classificadas em 4 eixos.

O eixo I tem como foco a implantação da rede de internet banda larga no país, a um preço acessível. O principal exemplo nesse eixo é o Programa Nacional de Banda Larga. O eixo 2 possui a maior parte das ações e visa disponibilizar o acesso público e gratuito à internet. Os programas de destaque são os de Telecentros Comunitários.

Já o eixo 3 é representado pelo Programa Cidades Digitais, que propõe a instalação de redes digitais de alta velocidade em prefeituras, o fornecimento de aplicativos de governo eletrônico e a disponibilização de acesso de pontos gratuitos para uso livre da internet. $\mathrm{O}$ quarto eixo é dedicado a projetos de formação e capacitação para uso das tecnologias.

Vale destacar que muitas vezes a falta de articulação e integração entre as ações se dá por causa de interesses políticos. Prefeituras, Estados e o Governo Federal acabam por não se alinharem em bons programas devido a conflitos eleitoreiros. Para suprir esse problema, são necessárias políticas estatais de longo prazo que utilizem o melhor da experiência nacional e internacional e, por fim, baseada em critérios técnicos e com objetivos e resultados bem definidos.

Na cidade de São Paulo, o programa Wi-Fi Livre vem chamando a atenção. Nele os usuários podem utilizar a Internet gratuitamente em diversos pontos da cidade. O projeto que começou em 2018 não prevê desembolsos da prefeitura, mas sim o fornecimento dos 
serviços por empresas privadas, que em contrapartida podem explorar a publicidade digital ${ }^{8}$.

As empresas que aderem ao programa devem fornecer um serviço de qualidade, que permita ao usuário acessar vídeos, redes sociais e sites em geral. Além disso, o cidadão pode pular a publicidade após io segundos.

Mas não é só na maior cidade do país que a ideia é viável. No Maranhão, por exemplo, uma iniciativa parecida, chamada de MaraNet, pretende levar Wi-Fi grátis para diversos pontos do Estado onde haja grande circulação de pessoas ${ }^{9}$.

Contudo, é importante destacar que as ações não precisam partir exclusivamente do Estado. Há vários projetos de internet comunitária sendo executados pelo país. Neles, os próprios usuários fazem a gestão da rede e dividem entre si o custo de estrutura, o que torna muito mais barato do que as formas tradicionais de acesso oferecidas por grandes provedores.

Há diversas iniciativas pelo país, como as de São Paulo e do Maranhão, que demonstram que com vontade política é possível democratizar o acesso à Internet e promover desenvolvimento social. Observando a importância da rede nos dias atuais, fica fácil entender seu poder transformador e concluir que expandir seu acesso gera um ciclo positivo para o cidadão e para a sociedade em geral.

\section{CONCLUSÃO}

A Internet foi um verdadeiro divisor de águas na vida em sociedade, assim como a escrita e a matemática. Ela é composta por sua estrutura física e por suas aplicações, que representam a parte mais conhecida pelos usuários. Hoje, há dois mundos completamente diferentes: um composto por pessoas que tem acesso à rede e outro, por indivíduos que não tem. Diante desse fato, o mundo jurídico e o Estado não podem ficar inertes.

$\mathrm{Na}$ evolução do Homem, a luta por direitos tem sido uma constante e é nesse cenário que os direitos fundamentais surgiram. Diante da importância da Internet e da natureza dos direitos fundamentais, parece claro que a rede mundial de computadores merece um lugar nesse rol de direitos.

Além disso, a Internet pode ser considerada uma garantia fundamental, ou seja, um mecanismo que garante a efetivação de outros direitos. Os direitos políticos, por exemplo, que são a base do Estado Democrático estão sendo exercidos atualmente tendo a internet como ponto focal. Os espaços institucionais tradicionais vêm perdendo espaço.

Para efetivar o acesso à internet o Estado deve assumir papel importante: de um lado adotar políticas para aumento da inclusão digital, de outro oferecer garantias de não interferência no domínio privado da internet. Tarefas que, apesar de não serem fáceis, já vêm sendo executadas no Brasil.

\footnotetext{
${ }^{8}$ WI-FI LIVRE SP. Sobre o Programa. Disponível em: https://wifilivre.sp.gov.br/programa.html. Acesso em: 13 jul. 2019.

9 GOVERNO DO MARANHÃO. Cidadania Digital (MARANET). Disponível em: http://www.secti.ma.gov.br/wifi-gratis/. Acesso em: 20 jul. 2019. 
Conclui-se, portanto que o acesso à Internet é um direito fundamental, importantíssimo para o desenvolvimento humano e para uma vida plena em sociedade. 6 Referências

BBC. Entenda o escândalo de uso político de dados que derrubou valor do Facebook e o colocou na mira de autoridades. Disponível em: https://www.bbc.com/portuguese/internacional-43461751. Acesso em: 13 jul. 2019

BBC. Finlandeses passam a ter acesso a banda larga garantido por lei. Disponível em: https://www.bbc.com/portuguese/noticias/2010/o7/1007oI_finlandia_banda_larga_mv.

Acesso em: 20 jul. 2019.

BOBBIO, Norberto; A Era dos Direitos. 7. ed. Rio de Janeiro: Campus/Elsevier, 2004. p. 2I-2I.

BRASIL. Constituição da República Federativa do Brasil: texto constitucional promulgado em 5 de outubro de 1988, com as alterações determinadas pelas Emendas Constitucionais de Revisão $n^{o s}$ i a 6/94, pelas Emendas Constitucionais nos $1 / 92$ a 96/2017 e pelo Decreto Legislativo no ${ }^{\circ} 86 / 2008$. - Brasília: Senado Federal, Coordenação de Edições Técnicas, 2017.

BRASIL. Lei no ${ }^{12.965}$, de 23 de abril de 2014. Marco Civil da Internet. Brasília

Brasil. Lei $\mathrm{n}^{\circ}$ 13.709, de 14 de agosto de 2018. Lei Geral de Proteção de Dados Pessoais. Brasília.

CASTrO, J.L. Cascajo, LUÑO, Antonio-Enrique Pérez, CID, B. Castro, TORRES, G. Gomes. Los derechos humanos: significacion, estatuto jurídico y sistema. Sevilha: Universidade de Sevilha, 1979. p. 43) Apud, MORAES, Alexandre de, op. cit. p.40.

CETIC - PORTAL DE DADOS. TIC Domicílios - 2017: Individuos. Disponível em: https://www.cetic.br/tics/domicilios/2017/individuos/CI/. Acesso em: 23 jun. 2019.

CONGRESSO EM FOCO. Kajuru usa as redes sociais para definir voto a presidente do senado. Disponível em: 〈https://congressoemfoco.uol.com.br/legislativo/kajuru-usa-asredes-sociais-para-definir-voto-a-presidente-do-senado/>. Acesso em: 23 mar. 2019.

DELOITTE. Value of Connectivity: Economic and Social Benefits of Expanding Internet Access. munications/2014_uk_tmt_value_of_connectivity_deloitte_ireland.pdf. Acesso em: 13 jul. 2019

EL PAÍS. A onda expansiva desatada por Snowden. Disponível em: https://brasil.elpais.com/brasil/2013/12/20/internacional/1387542392_057942.html. Acesso em: I4 jul. 2019. 
ÉPOCA NEGÓCIOS. Rússia quer criar a sua própria rede de internet, para se desconectar do resto do mundo. Disponível em: https://epocanegocios.globo.com/Tecnologia/noticia/2019/o3/russia-quer-se-isolar-dainternet-global-e-isso-custara-caro-e-enfrentara-barreiras-tecnicas.html. Acesso em: 2I jul. 2019.

EXAME. A era das fábricas inteligentes está começando. Disponível em: https://exame.abril.com.br/revista-exame/a-fabrica-do-futuro/. Acesso em: 22 jun. 2019.

EXAME. Internet é principal forma de achar emprego no Brasil. Disponível em: https://exame.abril.com.br/tecnologia/internet-e-principal-forma-de-achar-emprego-nobrasil/. Acesso em: 26 out. 2019 .

FERRAJOLI, Luigi. Por uma Teoria dos Direitos e dos Bens Fundamentais. I. ed. Porto Alegre: Livraria do Advogado, 20II.

FOLHA DE SÃO PAULO. Montadoras disputam com teles na Europa como conectar carros entre si. Disponível em: <https://m.folha.uol.com.br/mercado/2017/II/1935327montadoras-disputam-com-teles-na-europa-como-conectar-carros-entre-si.shtml >. Acesso em: 23 mar. 2019.

GLOBO.COM. ONU afirma que acesso à internet é um direito humano. Disponível em: http://gi.globo.com/tecnologia/noticia/20II/o6/onu-afirma-que-acesso-internet-e-umdireito-humano.html. Acesso em: 20 jul. 2019.

GOVERNMENT, Dubai School Of. Civil Movements: The Impact of Facebook and Twitter. Arab Social Media Report, [S.L], v. I, n. 2, mai./mar. 2019.

GSMA. The Mobile Economy 2019. Disponível em: https://www.gsma.com/r/mobileeconomy/. Acesso em: 23 jun. 2019.

INSTITUTO BRASILEIRO DE GEOGRAFIA E ESTATÍSTICA. Pnad contínua tic 2017: internet chega a três em cada quatro domicílios do país. Disponível em: <https://agenciadenoticias.ibge.gov.br/agencia-sala-de-imprensa/2013-agencia-denoticias/releases/23445-pnad-continua-tic-2017-internet-chega-a-tres-em-cada-quatrodomicilios-do-pais >. Acesso em: 23 mar. 2019.

INSTITUTO HUMANITAS UNISINOS. A Terceira Revolução Industrial. Entrevista com Jeremy Rifkin. Disponível em: http://www.ihu.unisinos.br/noticias/5ro884-aterceira-revolucao-industrial-entrevista-com-jeremy-rifkin\%2o. Acesso em: 22 jun. 2019.

INTERNATIONAL TELECOMMUNICATION UNION. New itu statistics show more than half the world is now using the internet. Disponivel em: 〈https://news.itu.int/itu-statistics-leaving-no-one-offline/〉. Acesso em: 23 mar. 2019. 
INTERNET SOCIETY. Brief History of the Internet. Disponível em: $\langle$ https://www.internetsociety.org/internet/history-internet/brief-history-internet/>. Acesso em: 20 jun. 2019.

KUROSE, Jim F.; ROSS, Keith W.. Redes de Computadores e a Internet: uma abordagem top-down. 6. ed. São Paulo, SP: PEARSON, 2014.p. 3

LEMOS, Ronaldo; FELICE, Massimo Di. A Vida em Rede. I. ed. Campinas, SP: Papirus 7 Mares, 2015. p. II

LUÑO, A. E. P. Teledemocracia, Ciberciudadania y Derechos Humanos. REvista Brasileira de Políticas Públicas, Brasília, v. 4, n. 2, p. 8-46, jan./2014.

MARMELSTEIN, George. Curso de Direitos Fundamentais. 7. ed. São Paulo: ATLAS, 2018

MASLOW, A. H. A theory of human motivation. Psychological Review, n. 50, de 1948, p. 370-396.

MENDES, Gilmar Ferreira; BRANCO, P. G. G. Curso de Direito Constitucional. 7. ed. São Paulo: Saraiva, 2012.

MORAES, Alexandre de. Direitos humanos fundamentais: comentários aos arts. I.. a $5 .^{\circ}$ da Constituição Federativa do Brasil, doutrina e jurisprudência. Teoria Geral. São Paulo: Atlas, 1997.

O GLOBO. IBGE mostra o que brasileiro mais faz na internet. Disponível em: https://oglobo.globo.com/economia/ibge-mostra-que-brasileiro-mais-faz-na-internet-masvoce-ja-sabe-resposta-22416939. Acesso em: 24 jun. 2019.

OPEN NET INITIATIVE. Internet in the middle east and north africa. Disponível em: https://opennet.net/research/regions/mena. Acesso em: 28 set. 2019.

PAULO, Vicente; ALEXANDRINO, Marcelo. Resumo de direito constitucional descomplicado. Io. ed. São Paulo: Método, 2016. 453 p.

ROSA, António Machuco. As origens históricas da Internet: uma comparação com a origem dos meios clássicos de comunicação ponto a ponto. Estudos em Comunicação, Porto, v. I, n. II, p.95-123, maio 2012.

SOUZA, Carlos Affonso; LEMOS, Ronaldo. Marco Civil da Internet: Construção e Aplicação. I. ed. Juiz de Fora: Editar, 2016.

SUPER INTERESSANTE. Como funciona a censura na China?. Disponível em: https://super.abril.com.br/mundo-estranho/como-funciona-a-censura-na-china/. Acesso em: 2I jul. 2019 . 
THE SUN. Does North Korea have internet and smartphones? An inside look at the wacky tech in Kim Jong-un's hermit kingdom. Disponível em: https://www.thesun.co.uk/tech/6156327/north-korea-internet-smartphones-technologykim-jong-un/. Acesso em: 26 out. 2019.

TRIBUNAL DE CONTAS DA UNIÃO. Política pública de inclusão digital. Disponível em:

<https://portal.tcu.gov.br/lumis/portal/file/filedownload.jsp?fileid=8a8182a1500586020150I f69co7e6boa\&inline = I $>$. Acesso em: 23 mar. 2019.

UNIVERSO ONLINE - UOL. Internet das Pessoas. Disponível em: https://www.uol.com.br/tilt/reportagens-especiais/uma-internet-para-chamar-denossa/index.htm\#com-a-internet-ninguem-precisa-morrer-para-denunciar-crimes. Acesso em: I7 set. 2019.

WORLD ECONOMIC FORUM. 6 ways the Internet of Things is improving our lives. Disponível em: https://www.weforum.org/agenda/2018/ol/6-ways-the-internet-of-thingsis-improving-our-lives. Acesso em: 24 jun. 2019. 